\title{
Comunicação midiática e educação na cibercultura
}

\author{
Mediatic communication and education in cyberculture
}

\author{
Antonio Francisco Magnoni ${ }^{[a]}$, Daniele Fernandes ${ }^{[b]}$ \\ [a] Jornalista, doutor em Educação pela Faculdade de Filosofia e Ciências da Universidade Estadual Paulista (FFC-UNESP), professor do \\ Departamento de Comunicação Social da Faculdade de Arquitetura, Artes e Comunicação da Universidade Estadual Paulista (FAAC- \\ UNESP), Bauru, SP - Brasil, e-mail: afmagnoni@faac.unesp.br \\ [b] Arquiteta, doutora em Comunicação e Semiótica pela Pontifícia Universidade Catpolica de São Paulo (PUC-SP), professora do \\ Departamento de Comunicação Social da Faculdade de Arquitetura, Artes e Comunicação da Universidade Estadual Paulista (FAAC- \\ UNESP), Bauru, SP - Brasil, e-mail: cyberdany@gmail.com.br
}

\section{Resumo}

Este artigo tem por objetivo discutir como a comunicação pode contribuir de forma efetiva com a educação na cibercultura, por meio do projeto de ambientes educativos que se configurem conforme a linguagem específica do ciberespaço. Consideramos as tecnologias digitais como linguagem e, portanto, como formas de comunicação. Como base teórica, utilizamos a semiótica peirceana, para as questões referentes à linguagem; o conceito de tecnologias da inteligência, para a relação da técnica com mídias digitais e os conceitos de emergência e de arquitetura transmissível para pensar as interfaces comunicacionais do ciberespaço. Fizemos uma breve reflexão sobre os entraves políticos, administrativos, sociais, culturais e econômicos que impedem o desenvolvimento de formas de educação mais apropriadas à cibercultura. Depois, apontamos algumas aproximações entre os campos da educação e da comunicação e fizemos algumas observações sobre qualidades das mídias digitais que podem contribuir para o melhor aproveitamento delas como ferramenta educacional. Finalmente, indicamos uma abordagem educativo-comunicacional dos games como uma possível saída para fazer das tecnologias comunicacionais interfaces audiovisuais interativas, capazes de educar na era da cibercultura.

Palavras-chave: Comunicação midiática. Cibercultura. Educação. Games. 


\begin{abstract}
This article aims to discuss how communication can contribute effectively with education in cyberculture, by design of educational environments that are configured according to the specific language of cyberspace. We consider digital technologies as language and therefore as forms of communication. As a theoretical basis, we use Peircean semiotics, for questions relating to language; the concept of technologies of intelligence, to the relation of the technique with digital media and the concepts of emergency and of transmiting architecture to think of cyberspace communication interfaces. We made a brief reflection on the political, administrative, social, cultural and economic problems that binder the development of more appropriate forms of education for cyberculture. Then we point out some similarities between the fields of education and communication and made some observations about qualities of digital media that can contribute to a better use of it as an educational tool. Finally, we indicate an educational and communicational gaming approach as a possible way to make communication technologies interactive audiovisual interfaces, able to educate in the age of cyberculture.
\end{abstract}

Keywords: Mediatic communication. Cyberculture. Education. Games.

\section{Introdução}

A cibercultura traz consigo, junto com o desenvolvimento tecnológico, toda sorte de modificações culturais, tornando possível uma profunda revolução nos nossos hábitos de pensar, de viver e, claro, de aprender. Entretanto, no caso específico da educação, parece que, na maioria das vezes, o que ocorre é uma mera transposição abrupta da maneira tradicional de ensinar para as mídias digitais. Utilizar aplicações conceituais e metodológicas da comunicação, uma área de conhecimento complexa que abrange arte, filosofia e ciência, talvez possa ajudar a estabelecer hipervínculos entre educação e cibercultura na realização de intervenções no ciberespaço.

Mencionamos dois termos-chave, ciberespaço e cibercultura, que devemos definir com precisão, como tópicos essenciais para o desenvolvimento de nossa reflexão. O ciberespaço é o meio de comunicação que surge com a interconexão mundial dos computadores, não representa só a infraestrutura, ele agrega as informações que difunde e a infinidade de pessoas que navegam nas suas páginas e que também o alimentam com múltiplos conteúdos e com tantos recursos colaborativos. A cibercultura é o conjunto de técnicas (materiais e intelectuais), de práticas, de atitudes, de modos de pensamento e de valores que se desenvolvem com o ciberespaço (LÉVY, 1999, p.17).

Em primeiro lugar, devemos lembrar que a mera digitalização de uma determinada narrativa, seja ela oral, escrita, visual, sonora, videográfica, fotográfica etc., não permite desenvolver todas as qualidades e os potenciais comunicativos específicos da linguagem digital. Não menosprezamos a importância do procedimento de conversão de conteúdos analógicos para suportes digitais. Afinal, ao serem publicados na internet e acessados por multidões, acervos inteiros podem ser protegidos do esquecimento e da deterioração. Entretanto, as obras digitalizadas e publicadas na internet não traduzem o pensamento próprio da cibercultura. Elas são pensadas em e para um contexto distinto.

Falamos anteriormente sobre uma maneira empírica de interpretar os meios digitais como plataformas de disseminação de informações e de conhecimentos. Temos percebido que esse pode ser o principal nó da questão: na cibercultura, a educação permanece mais vinculada ao campo da disseminação de conhecimentos previamente estabelecidos e menos ligada aos meios e processos de produção dele. As atividades educativas não deveriam estar mais relacionadas à interação não linear do que a uma transmissão vertical hierarquizada? As ações de ensino e de formação cultural não estariam mais relacionadas ao desenvolvimento da autonomia individual, numa experimentação que produz encontros, sínteses e novos saberes, do que à trivial difusão de um saber previamente constituído e institucionalizado? Disponibilizar conteúdos online não significa romper com essa forma conservadora e padronizada 
de ensinar e de aprender. Isso talvez corresponda mais ao ensino instrumental, ao adestramento prático e funcional, do que à educação verdadeiramente emancipadora.

\section{A complexidade da problemática comunicação-educação}

Com a popularização das recentes redes sociais, antigas categorias funcionalistas de difusão de mensagens em veículos de massa vão perdendo seus significados originais, derivados de formas unilaterais, verticalizadas e comerciais. Há um ocaso gradual do padrão autoritário e mercantil, surgido com a imprensa e que foi posteriormente incorporado pelo rádio e pela televisão. Cada nova versão da web renega os velhos sistemas de instrução programada, em que a interação entre o estudante e o conteúdo estava restrita a uma dinâmica de ensino-aprendizado baseada em estímulos e respostas preestabelecidas e praticadas com o uso de suportes pedagógicos bastante limitados. A rede de computadores dispõe da vantagem incomparável de ser um meio audiovisual com recursos para propiciar comunicação multilateral e colaborativa, que permite ao internauta a sensação de efetiva presença em uma atividade da qual ele esteja participando em tempo real. Outra virtude "pedagógica" da internet é que os conteúdos disponíveis estão vinculados à percepção lúdica coletiva, à cultura universal de entretenimento. A educação será revolucionária quando houver mais prazer em educar e em aprender.

No entanto, de que adianta falar de tecnologia informacional tão flexível e com tantas possibilidades pedagógicas se elas continuarem distantes dos sistemas educacionais brasileiros? Enquanto a Educação pública brasileira perpetua suas contrariedades, a atualização tecnológica dos meios informacionais prossegue acelerada. A construção de conexão apropriada entre os meios informacionais e os sistemas de ensino, do nível básico ao superior, é estratégica para que o Brasil consiga participar ativamente da era digital. Mas colocar em prática qualquer modalidade possível de Educação Assistida por Recursos Informáticos e Audiovisuais (EARIA) depende da resolução objetiva das questões conceituais e político-administrativas, que envolvem os sistemas e as concepções educacionais brasileiras.
Além disso, é preciso que educadores e comunicadores realizem esforço permanente para desenvolver uma cultura hipermediática cotidiana em todos os níveis educacionais. Há concordância quase unânime, tanto no meio escolar quanto no meio social, da necessidade e da importância, em todos os contextos da vida cotidiana, de se ter domínio atualizado das tecnologias e dos conhecimentos técnico-científicos compatíveis com as múltiplas atividades das pessoas. Então, será preciso desenvolver ações para capacitar professores pouco familiarizados com o manejo das tecnologias, das linguagens e dos formatos adequados para a difusão dos conteúdos hipermidiáticos educativos. Só com a aquisição de base razoável de conhecimento tecnológico e de senso crítico, um professor poderá utilizar e produzir ferramentas, softwares, linguagens, formatos e conteúdos que se adéquem à prática didático-pedagógica e à realidade sociocultural dos alunos.

Dentro dessa perspectiva, entendemos a necessidade de considerar as tecnologias de informação e comunicação como fundamentais para a constituição de métodos pedagógicos. Eis o lado político da Educação Assistida por Recursos Informáticos e Audiovisuais (EARIA): a questão não é treinar, mas dar meios para a autonomia dos educadores e comunicadores. São milhares de profissionais que deverão ter condições para se atualizar regularmente para exercer a função de formadores sociais hipermidiáticos. A formação do educador não poderá ser exclusivamente técnica, mas teórico-prática. Antes de conhecer as máquinas é preciso que o professor conheça profundamente os princípios gerais que determinam a revolução informacional.

[...] o conceito de alfabetização não pode ser explicado só em função de seus aspectos psicológicos. Soares (1995) explicita a fundamental abordagem dos aspectos sociais desse conceito, uma vez que o sucesso ou o fracasso das iniciativas nessa área estão intimamente ligados a questões sociais, culturais, políticas e econômicas. Neste sentido, pode-se dizer que Paulo Freire exerceu papel determinante na ampliação do conceito de alfabetização no Brasil e no mundo. [...] É [ele] que introduz entre nós a noção de que ler a palavra é ler o mundo. Através do contato com o mundo escrito o sujeito apreende mais sua cultura e 
nela se insere com maior poder de atuação. Hoje, ler o escrito não basta. Para ler o mundo é necessário ler as mensagens tecnológicas e sua interferência nas formas de organização de nossa sociedade e nossa cultura (SAMPAIO; LEITE, 2000, p. 54-5).

Pelo que dissemos anteriormente, vemos que existe a necessidade de os métodos educacionais evoluírem junto com a cultura; mas, por outro lado, existe um choque entre a geração dos "imigrantes digitais" e a dos "nativos digitais", termos cunhados por Prensky (2001). Os imigrantes digitais nasceram na era analógica e os nativos digitais são a geração que nasceu na era digital, a partir de 1980. Os nativos são acostumados a receber informação muito rápido, fazem muitas coisas ao mesmo tempo e lidam bem com processos não lineares, preferem as informações visuais às verbais, funcionam melhor em rede e gostam de aprender por meio de atividades baseadas em jogos. A exigência de concentração em um só foco, ligada a formas tradicionais de ensino, por exemplo, provoca monotonia, dispersão e desinteresse nos nativos digitais. Segundo Mattar, os nativos digitais

preferem se auto-educar; ignoram a educação formal; tendem a utilizar o método da tentativa e erro; preferem aprender pela interação com os colegas a aprender com autoridades; consomem o aprendizado pouco a pouco, quando querem, em geral quando uma habilidade é necessária; e preferem aprender na prática a aprender por manuais (MATTAR, 2010, p. 14).

Para designar essa nova geração que "zapeia" por diversas plataformas tecnológicas, Veen e Vrakking cunharam o termo "Homo zappiens", que "é um processador ativo de informação, resolve problemas de maneira muito hábil, usando estratégia de jogo, e sabe se comunicar muito bem. Sua relação com a escola mudou profundamente... o Homo zappiens é digital e a escola é analógica." (VEEN; VRAKKING, 2009, p. 12).

Os profissionais da educação deveriam ser os primeiros a conhecer as possibilidades didático-pedagógicas, comunicativas, culturais e produtivas das mídias digitais, especialmente das que são baseados em jogos, preferência nítida das novas gerações, conforme mencionado nos dois últimos trechos citados. Afinal, a educação transformadora deve ser processo capaz de unir organicamente ensino com conteúdos atuais e práticas atraentes de aprendizagem. Para os docentes, é um desafio cada dia mais árduo motivar e possibilitar a formação consistente e atualizada de seus alunos: eles nascem e crescem sob a influência cotidiana da cultura midiática digital contemporânea que evolui de forma extremamente acelerada.

Entretanto, historicamente, comunicação e educação parecem ser vistas como coisas antagônicas. Antes de tudo, convém lembrar que o desenvolvimento da imprensa, da publicidade, do rádio e da televisão foi sempre determinado por um único objetivo: tais veículos facilitaram a inserção das populações mundiais nos modos de vida preconizados pelo ordenamento urbano-industrial capitalista. Isso acaba fazendo com que as tecnologias da comunicação sejam usadas de maneira a não privilegiar a educação, principalmente porque ela poderia levar ao questionamento das próprias estruturas sociais e econômicas.

Desde o surgimento da comunicação radiofônica nos anos 1920, houve uma inversão de papéis: de influenciadoras, a escola e as instâncias formais de cultura passaram a ser influenciadas pelos meios audiovisuais de comunicação. Tal influência tornou-se cada vez mais presente no espaço escolar, principalmente, com o fascínio que eles exercem sobre crianças e jovens. O impasse entre a comunicação midiática e a educação, um conflito nunca declarado publicamente, atravessou todo o século XX - um dissenso descabido entre dois espaços de atuação cultural pública, entre dois ambientes profissionais, cujos trabalhadores são pertencentes à mesma categoria de produção não material.

Comunicadores e educadores realizam trabalhos da mesma natureza e com objetivos bastante comuns. Então, qual a origem lógica do distanciamento e até do antagonismo entre a comunicação e a educação? Tardy (1976) é demolidor ao criticar a rejeição dos professores aos meios de comunicação: "a pedagogia é uma máquina de dizer não e caminha sempre em círculos. Os intelectuais consideram o território das imagens um campo depreciativo. A pedagogia tradicional é mental e verbal..." Porém, a rejeição da escola aos meios de comunicação audiovisuais não atrapalhou o desenvolvimento destes. 
Tardy ressalta que o cinema não tem paternidade cultural (derivado da antiga diversão da "lanterna mágica" e das exibições de prestidigitadores), nasceu nas quermesses, nos subúrbios e desenvolveu-se sem a ajuda dos homens da cultura. E Morin (1962, p. 258) advoga que "é preciso conhecer este mundo, sem nos sentirmos estranhos nele. É preciso flanar (sem preconceitos) pelas grandes avenidas da cultura de massa".

Concluindo, sequer adianta tentar fugir da convivência com as mídias. O mundo real anda tão midiatizado que nem é preciso que os professores deixem o espaço escolar ou o de suas casas para travarem contato com o mundo da comunicação. E os pedagogos podem percorrer o mundo todo pelas redes sociais, mas apenas isso não irá reaproximar a educação da comunicação porque tal distanciamento não deriva de incompreensões mútuas que poderiam ser apaziguadas com mero esforço diplomático. O distanciamento entre as duas áreas é, sobretudo, conceitual, epistemológico, metodológico e também político.

\section{Aprender a se comunicar por meio das tecnologias digitais}

O desafio para a educação mediada por tecnologias digitais esbarra na dificuldade do uso da tecnologia como forma de comunicação educacional. Isso ocorre tanto devido ao aspecto teórico-prático da comunicação audiovisual, quanto devido a problemas no campo conceitual e metodológico da educação. Se, durante uma teleconferência, por exemplo, colocamos um professor falando diante de uma câmera e transmitimos "a seco" para os estudantes, o esquema da teleaula será idêntico ao de uma aula presencial e até os estudantes poderão fazer as perguntas usuais pelos canais de retorno. Por outro lado, também existem aulas presenciais, sem que haja nenhum dispositivo digital, nas quais o professor consegue transmitir e, principalmente, construir conhecimentos, educando de uma maneira bastante afinada com as concepções da cibercultura e das práticas sociais contemporâneas. Queremos dizer que o problema está em saber usar as tecnologias, sejam elas quais forem, como meios de comunicação-educação.

Aqui é preciso ponderar que muitos ambientes de educação não presencial são concebidos apenas como ferramentas de inovação burocrática ou para servir como apelo mercadológico das instituições e não como instrumentos efetivos de inovação educacional. Enquanto outros ambientes, mesmo sendo comerciais, podem ser extremamente eficazes para a educação. Um exemplo disso é o Second Life que

está muito mais próximo de um ambiente de aprendizado que ferramentas "achatadas" como Blackboard ou Moodle. [...] um macro-ambiente composto de infinitos micro-ambientes, como universidades, museus, objetos, scripts, imagens, sons, texto etc. Ele pode certamente ser combinado com sucesso com outras ferramentas, mas não porque é incompleto, e sim porque combinar funciona muito bem nesse novo cenário da educação (MATTAR, 2008, p. 4).

Muitos estabelecimentos de ensino adotam sistemas digitais para fiscalizar se as atividades dos estudantes e professores foram desempenhadas corretamente e dentro dos prazos e modelos estabelecidos. Um tanto dos recursos que os ambientes de teleducação disponibilizam - lista de estudantes, agenda de atividades, datas de entrega, fóruns, arquivos, links de referências etc. - poderiam ser substituídos por instrumentos existentes fora dessas plataformas. Pois, conforme a citação de Mattar acima, "combinar funciona muito bem nesse novo cenário da educação". O uso de e-mail, planilhas, tabelas, editores de texto, blogs, chats, redes sociais, MSN, Skype, Youtube, celular etc., custaria menos e daria resultados mais eficientes, por serem ferramentas e softwares corriqueiros para os usuários de computadores e da internet. Com isso, queremos dizer que a web já oferece separadamente ferramentas capazes de dar conta das tarefas exigidas pelos sistemas de teleducação. A maneira como esses sistemas são construídos também está fundamentada nas formas convencionais de ensino-aprendizagem: passar o conteúdo, depois dar exercícios para fixá-lo, fazer a correção e atribuir nota.

Outro equívoco são os sistemas ditos interativos: aqueles nos quais podemos mandar mensagens com opiniões e sugestões ou, então, escolher entre alternativas preestabelecidas. Os sistemas digitais podem ser interativos; mas não o são necessariamente. Apertar botão não é sinônimo de interagir. Mandar mensagem via formulário ou e-mail 
terá o mesmo resultado que mandar uma carta ou telefonar. Apontamos em seguida, algumas questões elementares e fundamentais sobre interatividade:

a) Qual é o grau de intervenção que você pode ter em um sistema? Ele corresponde ao que você faz?

b) Existe alteração recíproca nos comportamentos dos que interagem?

c) Você interfere diretamente na percepção que você mesmo e outras pessoas têm do sistema ou precisa passar por uma pessoa que o administra?

d) E, principalmente, o sistema lhe permite criar alguma coisa ou apenas escolher entre possibilidades preexistentes?

Essa última pergunta nos leva diretamente a um assunto muito em voga ultimamente no Brasil: TV Digital. Pensamos que, da maneira como essa tecnologia está estruturada, a web acaba favorecendo muito mais a produção do conhecimento do que ela. A TV Digital ainda mantém a estrutura arborescente um-todos, típica do sistema broadcast, enquanto a web aperfeiçoa e amplia a estrutura rizomática e multilateral todos-todos. Claro que existem "truques": os sistemas de busca da web, por exemplo, direcionam os internautas, segundo o interesse dos patrocinadores desses sistemas. Mas a estrutura de base da web é colaborativa e expansiva. Com a web 2.0, qualquer um com um mínimo de conhecimento técnico de informática alimenta um blog com informações ou divulga o que pensa em redes sociais. Enquanto isso, na TV digital, por enquanto, podemos apenas responder enquetes e escolher dentre alternativas predeterminadas, mesmo que elas sejam muitas. Entretanto, em se tratando de interatividade na educação, temos o envolvimento da criatividade estética, comunicativa e reflexiva, que não aceita se subordinar tão facilmente às opções pré-moldadas.

Em resumo, pensamos que todas as vezes que alguém tenta transpor uma maneira de pensar própria de átomos analógicos para os bits, não está pensando para e com o meio digital. Quem age assim, apenas tenta ajustar o novo meio para acomodar um pensamento preexistente. No caso das tecnologias comunicacionais, o pensamento preexistente é o pensamento da cultura industrial. De todas as características dela, temos a hipótese de que duas delas são as que mais bloqueiam o processo de resgate do pensamento complexo e anticartesiano: a fragmentação e a hierarquização. Ambas agem a favor de uma concentração de poder, obtida pela restrição de informações. Fragmentação e hierarquização se relacionam intimamente: para alguém se colocar numa categoria superior da hierarquia, esse alguém poderá fragmentar o conhecimento, mostrar aos outros apenas o resultado pronto, não o processo que conduziu a tal resultado-como no modelo industrial fordista. Em outras palavras, tenta-se separar tudo em partes, evita-se estimular - de fato - o pensamento complexo, embora se fale muito a respeito dele. Não estamos falando aqui deste ou daquele conteúdo específico, mas do pensamento em si, da maneira de pensar que separa matemática de história, biologia de inglês, que separa pensar de agir e, o pior para a educação: que separa diversão de estudo. Nisso é perdido o que há de mais fundamental no processo do aprendizado: o prazer de pensar.

Com a fragmentação, perde-se a consciência do processo que produziu um determinado pensamento. Em outras palavras, o aprendizado convencional faz com que se acostume a receber pensamentos prontos. Não estimula a perceber que nada está pronto, que nisso se encontra o prazer do aprendizado e que aprender e criar são uma mesma coisa: construção de conhecimento. E um dos conhecimentos imprescindíveis a se construir nessa sociedade fundamentalmente comunicacional é o próprio conhecimento de como educar e se educar por meio da utilização criativa das tecnologias digitais.

\section{O ambiente imersivo do encontro}

As tecnologias digitais hipermidiáticas colaborativas, não hierárquicas e conectáveis - são propensas a colocar esse modelo "industrial" em xeque. Mas como saber, então, quando a tecnologia digital não é mera transposição de um modo de pensar atrelado à fragmentação e à hierarquização? Quando podemos vê-la como ferramenta educacional de fato? Quando ela é ferramenta de modificação cognitiva.

Ao falarmos sobre técnicas, estamos, na verdade, falando sobre tecnologias da inteligência. Para Pierre Lévy, cada nova tecnologia implica uma nova maneira de pensar e de conviver, assim, trata-se da construção de um coletivo pensante homens-coisas, 
economia cognitiva, e que, portanto, as tecnologias, como tecnologias da inteligência, podem ter muito a ensinar (LÉVY, 1993, p. 11). Todas as vezes que estamos diante de uma nova tecnologia, também estamos diante de uma possível crise para o pensamento. Cada tecnologia pode permitir a modificação na nossa maneira de pensar, podendo ser percebida e utilizada como uma ferramenta para o desenvolvimento cognitivo, em outras palavras, como linguagem.

Pela teoria peirceana, não existe pensamento sem linguagem, pois todo pensamento se dá em signos (SANTAELLA, 2001, p. 32) e não há como produzirmos linguagem sem nos voltarmos para os fenômenos. Há uma categoria fenomenológica, a da primeiridade, que está diretamente ligada ao raciocínio abdutivo, responsável pelo pensamento criativo. Do ponto de vista prático, essa categoria se vincula às qualidades estéticas características dos meios (SANTAELLA, 1994, p. 164). Assim, parece-nos que, não apenas no caso da tecnologia digital, mas no caso de todas as tecnologias já disponíveis e que venham a surgir, devemos partir das qualidades próprias a cada uma delas, se quisermos utilizá-las de forma criativa, ou seja, como linguagem, como maneira de pensar (FERNANDES, 2009, p. 152).

A tecnologia digital não tem como qualidades intrínsecas a fragmentação e a hierarquização. Pelo contrário, existe nela a possibilidade de conectar qualquer ponto a qualquer outro, independente de distância. Isso significa potencial para conectar qualquer pessoa a qualquer outra. Esta é a experiência de navegar: ir seguindo links sem saber aonde eles vão nos levar. E cada um pode colocar na web o que quiser e pode fazer conexões também com o que quiser. Evidentemente isso conduz a outros perigos, que não ao da censura. Isso também não garante que o ciberespaco seja um ambiente democrático de fato, apenas de direito. Há democracia sem educação?

A partir dessas qualidades das mídias digitais, podemos perceber que a estratégia de educação no ciberespaço deve ser a da colaboração sem hierarquia, onde mesmo um educador passa a ser, no máximo, um orientador, um mapeador; jamais um "doador" de conhecimento. É cada vez mais fácil encontrar informação; difícil é conseguir articular, indexar e organizar a informação para produzir conhecimento. O que importa, portanto, são as conexões. E aí está o ponto onde a comunicação pode contribuir com a educação na cibercultura. A comunicação estuda o pensamento como linguagem. No caso do ciberespaço, trata-se do pensamento expresso em uma linguagem audiovisual interativa. Sem o conhecimento dessa linguagem própria à cibercultura, não há como existir uma forma de educação propriamente contemporânea.

Apoiamos a tese defendida por Mattar (2008, p. 1) de que "a interação com os ambientes de aprendizagem foi sistematicamente ignorada pelos teóricos da EaD." Assim, vemos que existe grande urgência, por exemplo, em pensar a interface dos sistemas educacionais, interface como o ambiente imersivo do encontro, uma espécie de arquitetura transmissível, para utilizar o termo cunhado por Novak (1997, p. 261-265). Interface, portanto, não é entendida apenas como disposição de elementos numa tela de computador ou como reprodução de uma sala de aula, por exemplo, mas também como um ambiente de comunicação audiovisual interativa que favorece a colaboração entre as pessoas. Afinal, o que há de mais mágico nas tecnologias digitais talvez seja a anulação da distância pela supressão do tempo necessário para percorrê-la. Mas não podemos negar: embora não haja um "lugar" onde as pessoas se encontrem, ninguém nega a sensação de ter se encontrado com outra pessoa no MSN, num chat ou no Skype. Por isso, Johnson (2001) chamou nossa cultura de "cultura da interface", porque nosso espaço de encontro é a interface. Mas, do nosso ponto de vista, essa interface deve ter um desenho capaz de expressar as relações de força da cibercultura, as relações sociais; deve se constituir como um mapa aberto e conectável, interativo e colaborativo, complexo, heterogêneo.

Existe um conceito que faz transparecer o efeito que um mapa desse tipo pode produzir: a emergência. Ela tem a ver com o surgimento espontâneo e imprevisto de um comportamento de ordem superior, a partir de interações complexas entre agentes locais. Trata-se de uma forma de auto-organização. Um tipo de organização que independe de um líder, que emerge espontaneamente das próprias interações complexas entre elementos de uma rede, seja ela qual for, um sistema que Steven Johnson (2003, p. 14-5) chama de botton-up (de baixo para cima), como contraposição a top-down (de cima para baixo).

Já não é passada a hora de os próprios educadores entenderem que aprender é, na verdade, o mesmo que criar? Que cada um tem um caminho 
diferentes para fazê-lo? Já não é passada a hora de deixar transparecer que, às vezes, educadores aprendem mais com os estudantes do que vice-versa? De mostrar que não há realidade pronta, mas realidade por construir? De buscar a articulação transdisciplinar de conteúdos e competências imprevistas, não o foco em competências e conteúdos predefinidos? Será que não está na hora de pensar os sistemas educativos como sistemas capazes de se auto-organizar, como emergência, isto é, de baixo para cima e não de cima para baixo?

\section{Os games na educação}

Mas, enfim, como resolver, na prática, o problema do distanciamento entre comunicação midiática e educação? Ao longo do artigo, vimos que se trata de uma solução complexa, que envolve questões administrativas, políticas, econômicas, sociais, conceituais, metodológicas etc. Entretanto, nosso artigo estaria incompleto se não apontássemos uma possibilidade de ensino-aprendizagem essencialmente comunicacional e digital, como um exemplo conceitual e também aplicado.

Existe um produto, ainda pouco utilizado tanto pela comunicação quanto pela educação, mas com características comunicativas consolidadas e absorvidas socialmente, para ser aprimorado como ferramenta de uma "pedagogia da cibercultura", em uma proposta de educação menos hierarquizada, mais espontaneamente organizada e com capacidade de agregar conhecimentos díspares. Falamos dos games. Eles fazem forte oposição ao modelo de ensino-aprendizagem atual, centrado na figura do professor e com enfoque conteudista. Dentre as principais habilidades dos gamers apontadas por com Mattar (2010) e Prensky (2007) estão: facilidade para trabalhar em grupo; aprendizagem rápida; iniciativa, atitude e criatividade; capacidade de resolução de problemas e tomada de decisões com pouca informação; raciocínio e processamento de informações mais rápidos; pensamento não linear; preferência do visual ao textual; não ver fronteiras entre jogo, trabalho e estudo; sentimento positivo em relação à tecnologia e a conectividade; desenvolvimento de atividades simultâneas sem comprometimento do resultado de algumas delas.
A indústria dos gamesé uma das mais lucrativas do mundo e consegue tanto faturamento porque esse tipo de produto, por suas qualidades intrínsecas, é uma linguagem apta a expressar o pensamento da sociedade contemporânea, especialmente dos grupos sociais mais jovens. Ainda existe certa resistência dos educadores quando se fala em utilizar jogos eletrônicos na educação. Talvez isso ocorra pelo despreparo conceitual e técnico-didático dos mesmos e também pela associação dos games à violência, à cultura do entretenimento, da alienação e da dispersão social. Devemos lembrar que os games surgiram a partir dos simuladores de equipamentos bélicos e trouxeram consigo essa herança. Daí a maior parte deles ser relacionada aos combates. Entretanto, não há obrigatoriedade das narrativas seguirem essa linha.

Segundo Kafai apud Bittencourt e Giraffa, há basicamente duas abordagens para o desenvolvimento de jogos com propósitos educacionais: a instrucional e a construtivista. Na primeira, aprende-se algo enquanto se faz uma determinada atividade (integração do conteúdo que será ensinado com a ideia do jogo). Na segunda, os jogos são construídos pelos próprios estudantes utilizando-se ferramentas computacionais, muitas vezes, linguagem de programação. Os principais problemas motivacionais dos jogos educativos listados pelos jovens são os seguintes: carecem de desafios grandes e motivadores; baixo grau de imersão; por ser elaborados por pedagogos, os jogos enfatizam a educação, tornando pobres a interação e a parte gráfica; em geral, possuem baixa qualidade, pois são desenvolvidos com baixo orçamento (BITTENCOURT; GIRAFFA, 2003, p. 686).

Criada por Mihaly Csikszentmihalyi (1990), a Teoria do fluxo propõe diretrizes para produzir a motivação em diversas atividades, sem interesse em ganhos externos, mas em ganhos pessoais. O fluxo é um estado caracterizado pela imersão total e por um grande prazer; durante esse estado o indivíduo fica totalmente absorvido e focado na tarefa que está realizando, além de se sentir confiante e no controle da situação. As diretrizes são as seguintes: atividades desafiadoras, porém, superáveis; união pessoa-atividade; objetivos claros e feedback imediato; concentração e envolvimento despreocupado; despreocupação com o controle ou com o erro; perda da consciência do real; perda da percepção de tempo. Sweetser e Wyeth (2005) desenvolveram uma versão da Teoria do Fluxo voltada aos games: o "gameflow". 
Seus parâmetros são: concentração, desafio, habilidade, controle, objetivos claros, feedback, imersão e interação social. O estado de fluxo é favorável ao aprendizado e seus parâmetros se encontram presentes nos games comerciais. Talvez esteja aí o sucesso que estes fazem em relação aos chamados games educativos que não conseguem atingir o grau necessário de cada um desses parâmetros.

Uma saída para produzirmos games mais motivadores é o uso da Programação Orientada a Objetos (POO), que permite aos usuários dos games a modificação precisa de parâmetros para simular condições necessárias a estudos de caso. A orientação a objetos é um paradigma que foi desenvolvido a partir do campo dos estudos cognitivos e influenciou a inteligência artificial e a linguística (DAVID, 2007). Em resumo, um game programado segundo a concepção da POO pode funcionar, por exemplo, como um laboratório digital para disciplinas como física, matemática e até mesmo para a complexa biologia. Um laboratório lúdico produzido segundo o paradigma da orientação a objetos pode ser explorado e mesmo construído colaborativamente, sem as barreiras da distância física, sem a fragmentação do conhecimento e sem a hierarquização, podendo mesclar a abordagem instrucional e a construtivista. Pode proporcionar uma experiência de ensino-aprendizado em que tanto os educadores quanto os estudantes poderiam jogar como avatares nessa prazerosa interface de encontro, de educação e de comunicação.

\section{Considerações finais}

Pensamos muito no conteúdo que será transmitido, na maneira de avaliar, no tempo que será gasto nas atividades etc. Mas é precisamente do que é mais óbvio e próximo que mais nos esquecemos: a interface, o próprio ambiente midiático do encontro. Será que as nossas atuais interfaces educacionais conseguem incentivar o pensamento colaborativo, desfragmentado e não hierárquico? Será que elas constroem o espaço-tempo complexo, fluido, sincrético, interativo, lúdico, aberto, transdisciplinar e criativo que as tecnologias digitais híbridas podem proporcionar à educação? Temos as tecnologias, mas não compreendemos as implicações que elas têm como tecnologias da inteligência, como ferramentas educacionais capazes de produzir transformações cognitivas e culturais. Ainda não entendemos como deve ser a educação na cibercultura e para a cibercultura. E não vamos entender enquanto não formos capazes de olhar para o ciberespaço sem a "lente" fragmentária e hierarquizada que herdamos; enquanto não descermos do púlpito, não sairmos da frente do quadro (negro ou branco), enquanto permanecermos em salas de aula "quadradas", enquanto não nos tornamos, em alguma medida, gamers que produzem linguagem ao construir coletivamente o próprio ambiente hipermidiático que utilizam para se comunicar.

\section{Referências}

BITTENCOURT, J. R.; GIRAFFA, L. M. Modelando ambientes de aprendizagem virtuais utilizando role-playing games. Trabalho apresentado no XIV Simpósio Brasileiro de Informática na Educação - NCE - IM/UFRJ, Rio de Janeiro, 2003.

CSIKSZENTMIHALYI, M. Flow: The Psychology of Optimal Experience. New York: Harper Perennial, 1990.

DAVID, M. F. Programação orientada a objetos: uma introdução. 2007. Disponível em: < http://www.hardware. com.br/artigos/programacao-orientada-objetos $/>$. Acesso em: 26 jul. 2012.

FERANDES, D. Caleidoscorpi: percepção, diferença e interação no design de mídias digitais. 2009. Tese (Doutorado em Comunicação Semiótica) - Pontifícia Universidade Católica de São Paulo, São Paulo, 2009.

JOHNSON, S. Cultura da interface. Rio de Janeiro: Jorge Zahar, 2001.

JOHNSON, S. Emergência: a dinâmica da rede em formigas, cérebros, cidades e softwares. Rio de Janeiro: Jorge Zahar, 2003.

LÉVY, P. As tecnologias da inteligência: o futuro do pensamento na era da informática. Tradução de Carlos da Costa. Rio de Janeiro: Editora 34, 1993.

LÉVY, P. Cibercultura. Tradução de Carlos Irineu da Costa. São Paulo: Editora 34, 1999. 
MATTAR, J. Ambientes virtuais de aprendizagem 3D online: ensinando e aprendendo no Second Life. 2008. Disponível em: <http://www.abed.org.br/congresso2008/tc/ 532008123812PM.pdf>. Acesso em: 13 out. 2012.

MATTAR, J. Games em educação: como os nativos digitais aprendem. São Paulo: Pearson Prentice Hall, 2010.

MORIN, E. Essai sûr la culture de masse. Paris: Grasset, 1962.

NOVAK, M. Transmitting Architeture: The Transphysical City. In: Kroker, A.; Kroker, M. (Eds.). Digital Delirium. New York: St. Martin's Press, 1997. p. 261-271.

PRENSKY, M. Digital Natives, Digital Immigrants. MCB University Press, 2001. Disponível em: < http:// www.marcprensky.com/writing/Prensky $\% 20 \% 20$ Digital $\% 20$ Natives $\% 20$ Digital $\% 20$ Immigrants $\% 20-\% 20$ Part1.pdf>. Acesso em: 26 set. 2012.

PRENSKY, M. Digital game-based learning: practical ideas for the application of digital game-based learning. St. Paul, MN: Paragon House, 2007.

SAMPAIO, M. N.; LEITE, L. S. Alfabetização tecnológica do professor. Petrópolis : Vozes, 2000.
SANTAELLA, L. Estética: de Platão a Peirce. São Paulo: Experimento,1994.

SANTAELLA, L. Matrizes da linguagem e pensamento: sonora visual verbal. São Paulo: Iluminuras, 2001.

SWEETSER, P.; WYETH, P. GameFlow: A model for valuating player enjoyment in games. Computers in Entertainment, v. 3, p. 1-24, 2005.

TARDY, M. O professor e as imagens. São Paulo: Cultrix, 1976.

VEEN, W.; VRAKKING, B. HomoZappiens: educando na era digital. Porto Alegre: Artmed, 2009.
Recebido: 29/08/2012

Received: 08/29/2012

Aprovado: 25/10/2012

Approved: 10/27/2012 